\title{
Pibid Diversidade e a Formação de Educadores do Campo
}

\author{
Paulo Afranio Sant'Anna' \\ Luiz Otávio Costa Marques' \\ 'Universidade Federal dos Vales do Jequitinhonha \\ e Mucuri (UFVJM), Diamantina/MG - Brasil
}

RESUMO - Pibid Diversidade e a Formação de Educadores do Campo. O presente artigo configura-se como relato de experiência de procedimento descritivo-analítico. Ao discutir a formação do professor da educação básica no Brasil, destaca a necessidade do diálogo entre os processos formativos e o contexto das escolas públicas. Apresenta o Pibid como uma alternativa para o desenvolvimento de parte da trajetória formativa do docente nas escolas públicas. Diferencia o Pibid Diversidade como demanda das escolas do campo e indígena que visa fortalecer a construção de práticas pedagógicas em parceria com os sujeitos do campo. Discute o potencial desse programa para fortalecer o projeto de Educação do Campo em construção no país. Apresenta os resultados de um projeto desenvolvido na comunidade Santa Luzia, MG.

Palavras-chave: Formação do Professor. Pibid. Educação do Campo. Práticas Pedagógicas.

ABSTRACT - Pibid Diversidade and the Training of Countryside Education Teachers. This article is an experience report with a descriptive-analytical procedure. By discussing the education of K-12 teachers in Brazil, it highlights the need for a dialogue between educational processes and the context of public schools. It presents the Pibid as an alternative that enables that part of the teacher's training may take place in public schools. It differentiates the Pibid Diversidade as a demand of rural and indigenous schools which aims at the construction of pedagogical practices in partnership with subjects from the countryside. It discusses the potential of this program to strengthen the Countryside Education being built in Brazil. It presents the results of a project developed in the community of Santa Luzia, Minas Gerais state.

Keywords: Teacher Education. Pibid. Countryside Education. Pedagogical Practices.

Educação \& Realidade, Porto Alegre, v. 40, n. 3, p. 725-744, jul./set. 2015. 725 http://dx.doi.org/10.1590/2175-623645795 
A formação de professores para a educação básica é um grande desafio que precisa ser superado com políticas educacionais que fomentem a formação inicial e continuada dos docentes; que apresentem cenários atraentes para a inserção no mercado de trabalho com salários justos, com a valorização da prática docente e com escolas bem equipadas; que estimulem a pesquisa e o desenvolvimento de novas tecnologias de ensino e que favoreçam a implementação de projetos formativos inovadores e de qualidade, contempladores da diversidade social e cultural que compõe o cenário da educação no Brasil. Embora os dados do Censo Escolar da Educação Básica de 2014 (Brasil, INEP, 2014) indiquem uma crescente melhora na qualificação do quadro docente da educação básica, $24,22 \%$ deste não possui formação em nível superior. Do total de 2.148.023 professores, 520.391 não chegaram à universidade, sendo que 5.766 concluíram somente o ensino fundamental, 245.647 o ensino médio regular e 268.978 o normal/magistério. Dos 1.670 .352 graduados, 183.801 não cursaram licenciatura, portanto, não tiveram formação específica para a docência.

Segundo o resumo técnico do Censo Escolar da Educação Básica de 2012, publicado pelo Instituto Nacional de Estudos e Pesquisas Educacionais Anísio Teixeira (INEP):

\begin{abstract}
O Plano Nacional de Educação (PNE), em seu diagnóstico, define que a qualidade do ensino só poderá acontecer se houver a valorização dos profissionais do magistério, a qual só será alcançada por meio de uma política global capaz de articular a formação inicial, as condições de trabalho, o salário, a carreira e a formação continuada. O PNE conclui que a formação inicial e continuada do professor exige que o parque de universidades públicas tenha atenção especial à educação básica. Assim, a melhoria da qualidade da educação básica depende da formação de seus docentes, o que decorre diretamente das oportunidades oferecidas a eles. A melhoria na qualidade da formação dos professores com nível superior, por sua vez, está condicionada à qualidade da escolarização que lhes foi oferecida no nível básico, fechando um ciclo de dependência mútua, evidente e positiva entre os níveis educacionais (Brasil, INEP, 2013, p. 38).
\end{abstract}

Penin (2001), ao realizar revisão da história da formação de professores no Brasil, demonstra que as universidades públicas brasileiras assumiram muito tardiamente a tarefa de formar docentes para a educação básica. Nesse processo, as instituições privadas tiveram uma contribuição significativa, sendo responsáveis pela formação de um número expressivo de licenciados, porém, de forma precária, priorizando o ensino de teorias e práticas pedagógicas dissociadas da pesquisa e da extensão. As instituições públicas de ensino superior, por sua vez, trataram a formação de professores com menor importância dentro do contexto acadêmico. Ofertavam cursos fragmentados que se organiza- 
vam a partir de dois eixos que não interagiam entre si: as disciplinas pedagógicas e as disciplinas específicas, o que não permitia a construção da identidade profissional do professor ao longo do seu processo formativo.

Diante desse contexto, a autora destaca a importância de as universidades reestruturarem os seus cursos de formação de professores, considerando que as reformulações não podem se resumir a revisões curriculares, mas devem estar inseridas numa política global das universidades para a formação de professores que integre todas as unidades acadêmicas envolvidas nesse processo.

Os projetos de formação de professores devem considerar que a docência não ocorre num quadro abstrato de relações individualizadas de ensino e aprendizagem, e sim em um complexo contexto social e institucional.

As instituições escolares, embora em constante e forte diálogo com outras instituições sociais, têm história, valores, saberes e práticas sociais que lhes são específicos e, nesse sentido, têm um papel social peculiar. Não raramente, essa especificidade tem sido obscurecida pela incorporação acrítica de teorias, conceitos e perspectivas forjados a partir de outros interesses. [...] (A) especificidade das relações, problemas, valores e práticas sociais que historicamente caracterizam as instituições escolares não tem sido suficientemente reconhecida e problematizada. Importa, pois, que os princípios teóricos e práticos que norteiam a formação de professores afastem-se dessa simples transposição, voltando-se para a análise das peculiaridades históricas dessas instituições, de seus agentes sociais e das tarefas específicas de seus profissionais. Assim, uma política de formação de professores comprometida com os problemas escolares contemporâneos deve centrar-se num esforço de compreensão das práticas, dos valores e da história das instituições escolares e seus agentes institucionais, tendo em vista que essas escolas são as entidades concretas em que os futuros professores exercerão suas atividades (Penin, 2001, p. 327).

Portanto, formar professores capazes de responder à complexidade do contexto social, político e cultural contemporâneo exige um projeto de formação que priorize a construção de teorias e práticas alicerçadas na realidade escolar. Para isto, é preciso instrumentalizar o licenciando por meio de atividades de ensino, pesquisa e extensão, com teorias e métodos de investigação e intervenção que possam levá-lo a ler criticamente a realidade, a construir conhecimento e aprendizado a partir de situações reais e a problematizar a sua prática profissional, visando ao seu aperfeiçoamento e à sua formação continuada. Nessa perspectiva, "[...] a formação de professores deve ter na escola pública seu principal foco de interesse de estudo, investigação, acompanhamento, intervenção e melhoria da ação docente" (Penin, 2001, p. 327). 
O Pibid, Programa Institucional de Bolsas de Iniciação à Docência, se insere nessa lógica, possibilitando que parte da trajetória formativa do docente ocorra nas escolas públicas, inserida no cotidiano de professores e alunos e em confronto com os problemas reais que emanam da situação de ensino-aprendizagem e da gestão escolar. Dessa forma, antecipa o vínculo entre os futuros mestres e as salas de aulas da rede pública, esperando que boa parte destes venha a exercer o magistério nesse contexto.

Penin (2001), antecipando a criação do Pibid, sinalizou que:

Dado o caráter público da educação, o estabelecimento de vínculos entre os cursos de Licenciatura desta Universidade e as escolas das redes municipais e estadual constitui um instrumento importante para a formação de professores, para os serviços de extensão cultural e, em decorrência, para um esforço de aperfeiçoamento do ensino nessas instituições, bem como uma oportunidade ímpar para o afloramento e o cultivo de compromissos de nossos licenciandos com as instituições públicas de ensino (Penin, 2001, p. 327).

Além de favorecer uma trajetória formativa diferenciada, o Pibid faz uma articulação entre a educação superior, a escola e os sistemas estaduais e municipais de ensino. Essa articulação possibilita a construção de práticas educativas atualizadas e contextualizadas, pois envolvem todos os atores desse processo, assim como contribui para a gestão educacional nos seus diversos níveis. A universidade, como instituição formadora de profissionais da educação e produtora de conhecimento, pode contribuir de forma mais realista para a melhoria do ensino ao formar professores conectados com o cenário educacional no qual irão atuar e, ao mesmo tempo, produzir conhecimento que resulte em alternativas para os imensos problemas da educação básica no Brasil.

Ao oferecer bolsas aos licenciandos, aos professores da rede pública (supervisores) e aos professores universitários (coordenadores de área), o Pibid contempla três dimensões da formação do professor: a formação inicial, a formação continuada e a pesquisa/extensão. $O$ supervisor, que é um docente da escola onde o projeto é desenvolvido, passa a ser corresponsável pela formação do futuro professor. Essa função representa o reconhecimento e a valorização da prática do docente da rede pública, assim como um estímulo para o seu aperfeiçoamento.

Ao centralizar as suas ações nas escolas públicas, os projetos $\mathrm{Pi}$ bid impactam também na gestão dessas escolas que se deparam com demandas que surgem das novas propostas de ensino e aprendizagem. Espera-se que essas propostas contribuam para a formulação de políticas de gestão, tanto nas escolas como nos órgãos municipais e estaduais de educação.

No estudo de avaliação do Pibid publicado em 2014 (Fundação Carlos Chagas), verifica-se que o Pibid vem crescendo e se consolidan- 
do como estratégia de valorização da carreira docente. Em 2009, iniciou com 3.088 bolsistas oriundos de 43 instituições federais de ensino superior, alcançando, em 2014, o número de 90.254 bolsistas, distribuídos em 855 campi de 284 instituições públicas e privadas, sendo que 29 delas contam também com programas para as áreas da educação indígena e do campo (Pibid Diversidade).

A implementação do Pibid nas universidades brasileiras é um processo recente e demanda estudos de avaliação de seus impactos para a formação dos professores; para a melhoria da qualidade de ensino nas escolas públicas; para a valorização da carreira docente; para a formulação de políticas públicas de educação; para a construção de uma gestão escolar participativa; para a integração entre ensino, pesquisa e extensão na formação do docente, entre outros. No relatório acima citado (Fundação Carlos Chagas, 2014), apresenta-se um levantamento da produção acadêmica sobre o Pibid. Verificou-se, no ano de 2012, algumas pesquisas sobre o Pibid, sendo duas teses de doutorado, quinze dissertações de mestrado acadêmico e uma de mestrado profissional. Dessas, onze estudos são de instituições da região Sul e sete da região Sudeste, indicando um universo de estudo limitado e centralizado. As pesquisas contemplaram as áreas de Física, Química, Biologia, Matemática, Pedagogia e Letras. Nesse levantamento, não foi encontrado nenhum estudo que discuta e apresente resultados das ações do Pibid Diversidade.

Diante desse panorama, o presente artigo, constituído por um relato de experiência de procedimento descritivo-analítico, tem por objetivo discutir as especificidades e possibilidades do Pibid Diversidade e a sua relação com o projeto de Educação do Campo em construção no Brasil. Trabalha com as seguintes questões: Quais as propostas desse programa que podem dialogar e potencializar as estratégias metodológicas adotadas nas Licenciaturas em Educação do Campo? Como a construção de projetos nas escolas do campo pode influenciar na formação de uma identidade profissional vinculada às demandas sociais do campo? Qual o impacto dos projetos Pibid Diversidade na formação continuada aos docentes das escolas localizadas na zona rural? Quais os desafios para o efetivo diálogo entre o Pibid Diversidade e o projeto de educação do campo em construção no Brasil?

\section{Pibid Diversidade e Educação do Campo}

Atendendo às especificidades das licenciaturas interculturais indígenas e de educação do campo, a Coordenação de Aperfeiçoamento de Pessoal de Nível Superior (Capes) lançou, em 2010, o edital conjunto 002/2010/CAPES/SECAD-MEC - Pibid Diversidade, que acolheu projetos destinados às escolas indígenas e do campo. Nesse processo, foram aprovados 21 projetos com duração de dois anos. Além dos objetivos gerais do Pibid, o Pibid Diversidade visa “[...] propiciar um processo formativo que leve em consideração as diferenças culturais, a intercul- 
turalidade do país e suas implicações no trabalho pedagógico” (Brasil; CAPES, 2013). Para tal, fomenta a investigação docente no âmbito dos processos de ensino e aprendizagem com vistas à intervenção pedagógica e ao desenvolvimento de metodologias específicas para a diversidade sociocultural e linguística na perspectiva do diálogo intercultural.

A interculturalidade é uma proposta teórica que desafia congelamentos identitários e busca responder às questões advindas da diversidade cultural. Com essa intencionalidade, privilegia o múltiplo, o plural, as identidades marginalizadas e silenciadas e busca formas alternativas para sua incorporação na prática educacional.

O olhar multicultural trabalha com a valorização da diversidade cultural e o desafio a preconceitos, preconizando, em perspectivas mais recentes, sua articulação ao currículo escolar e de formação docente, de modo a não ser entendido apenas de forma apartada dos conteúdos ministrados em ambos os níveis educacionais e de formação. Outrossim, desenvolve, também, em suas visões mais críticas e pós-coloniais, a sensibilidade para o caráter híbrido da construção identitária, de modo a desafiar visões congeladoras e essencializadas das mesmas, que podem terminar por criar outros estereótipos na contramão do que se espera de uma perspectiva multicultural educacional (Batista; Silva Junior; Canen, 2013, p. 265).

A partir dessa perspectiva, espera-se que os cursos de formação de professores consigam formar profissionais com um perfil reflexivo, cuja prática se configura enquanto processo de ação-reflexão-ação, articulada às posturas investigativas multiculturais. "Tal perspectiva representa uma via pela qual as conexões entre o universo microssocial da sala de aula e a realidade cultural e social mais ampla possa se efetuar, possibilitando desafiar discursos que congelam identidades e reforçam preconceitos" (Batista; Silva Junior; Canen, 2013, p. 257).

Os projetos de educação voltados para as crianças da zona rural seguiram, até pouco tempo, a mesma lógica da educação desenvolvida no contexto urbano. A educação urbana, tomada como referência, não considera a diversidade sociocultural das populações que vivem no campo, seus saberes e modos de produção de vida. Ao valorizar a vida nas cidades, desqualifica a vida no campo e apresenta uma perspectiva limitadora para aqueles que nasceram e vivem no campo (Silva, 2010).

A partir da década de 90, tem início a construção de um projeto de educação voltado às populações historicamente silenciadas, os camponeses, indígenas, quilombolas, entre outras (Nascimento, 2009). Nesse processo, destaca-se o I Encontro Nacional de Educadores e Educadoras da Reforma Agrária - ENERA, realizado em 1997 pelo MST com o apoio da Universidade de Brasília e outros atores. Esse evento lançou as bases para a discussão de uma educação pública para os povos do campo que contemplasse a diversidade social, cultural, política e econômica 
dessa população. Colocam-se em debate as práticas educacionais construídas pelos sujeitos do campo, como a Pedagogia da Alternância, que possibilita incorporar outros espaços e tempos educativos integrando os modos de vida e saberes locais ao processo educacional. A partir dessas discussões, organiza-se, em 1998, a Conferência Nacional Por Uma Educação do Campo que possibilitou a criação da Articulação Nacional Por uma Educação do Campo.

Na perspectiva da educação do campo, os projetos de educação emanam das demandas que são formuladas pelos sujeitos sociais e são por eles articuladas e desenvolvidas. Ao contrário da educação rural que emanava da tecnocracia governamental, a educação do campo é um projeto construído com e para os sujeitos do campo.

Na formulação da educação do campo, o termo campo não se reduz ao local onde ocorre o processo educativo - as escolas rurais, mas se refere a uma concepção de território que vai muito além da delimitação de um espaço físico. Território, segundo Santos (2001), define-se pela forma como o espaço é ocupado pelo homem, portanto, inclui o fazer humano, a cultura, a economia, enfim, as formas de produção de vida. São lugares simbólicos constituídos pela diversidade cultural, pela pluralidade de geração e recriação de saberes e estratégias de sociabilidade.

Um projeto de educação que inclui a participação efetiva de todos os atores sociais deve prever também um modelo de formação de professores que dê conta de formar educadores com habilidade para fazer o resgate da memória e dos saberes locais, realizar a leitura crítica da realidade do campo, articular com a comunidade escolar e com os atores sociais alternativos para essa realidade e transformar essa experiência em conhecimento. O educador do campo deve ser capaz de construir um ambiente educativo que considere a diversidade dos grupos humanos e a sua relação com a terra, com a cultura e o mundo do trabalho, desse modo, valorizando o conhecimento dos diversos sujeitos da aprendizagem (Brasil, 2002).

O fazer da educação do campo pressupõe que a cultura tenha um lugar de destaque e seja entendida como um mapa por meio do qual as pessoas de um grupo pensam, classificam, valorizam e modificam o mundo e a si mesmas. Dentro dessa perspectiva, o processo educativo não se limita à escola:

\begin{abstract}
A Educação do Campo e no campo ocorre tanto em espaços escolares como fora deles. Envolve saberes, métodos, tempos e espaços físicos diferenciados. Portanto, não são apenas os saberes construídos na sala de aula, mas também aqueles construídos na produção, na família, na convivência social, na cultura, no lazer e nos movimentos sociais. A sala de aula é um espaço específico de sistematização, análise e de síntese das aprendizagens, se constituindo assim, num local de encontro das diferenças, pois,
\end{abstract}


é nela que se produzem novas formas de ver, estar e se relacionar com o mundo (Rocha; Passos; Carvalho, s/d, p. 8).

Os projetos de formação de educadores do campo devem, portanto, oportunizar espaços formativos que extrapolem os muros das universidades, que levem o discente a interagir com a diversidade do campo, com os seus saberes e formas de construção e apropriação do conhecimento. Insere-se, nesse contexto, a reflexão política sobre os projetos de campo em discussão no cenário brasileiro. Dessa forma, os objetivos do Pibid Diversidade somam-se aos do projeto pedagógico da Licenciatura em Educação do Campo, fortalecendo a proposta de formação contextualizada, engajada em uma política de valorização e melhoria da qualidade da vida no campo.

\section{Pibid Diversidade - UFVJM}

O Projeto Institucional Pibid Diversidade - UFVJM (Edital 02/2010) foi constituído por quatro subprojetos, desenvolvidos em oito escolas do campo, situadas em sete municípios do Vale do Jequitinhonha e norte de Minas Gerais: Almenara, Veredinha, Virgem da Lapa, Araçuaí, Vargem Grande, Montes Claros e Itamarandiba. Os subprojetos foram divididos em duas áreas de conhecimento: Ciências Humanas e Letras. O objetivo geral do projeto foi contribuir para a formação inicial e continuada de educadores do campo habilitando-os, a partir da leitura crítica da realidade do campo, a desenvolver uma prática pedagógica contextualizada e transformadora.

As atividades do projeto tiveram início em novembro de 2011 e terminaram em fevereiro de 2014. Foram desenvolvidas por uma equipe composta por quatro coordenadores de área, professores da Universidade Federal dos Vales do Jequitinhonha e Mucuri (UFVJM), oito supervisores (professores das escolas parceiras) e 34 bolsistas (discentes da Licenciatura em Educação do Campo). Para esse artigo, optamos por apresentar a experiência do subprojeto desenvolvido na comunidade Santa Luzia, localizada no município de Almenara, MG.

As ações realizadas compreenderam:

1. Capacitação dos licenciandos e dos professores supervisores das escolas parceiras na metodologia da pesquisa-ação que norteia as ações do projeto;

2. Análise das condições antropológicas, da história e do patrimônio material e imaterial das comunidades em que estão inseridas as escolas parceiras do projeto;

3. Análise das condições educacionais das escolas parceiras;

4. Levantamento das várias formas de expressão adotadas pelas comunidades atendidas;

5. Ações de mobilização da comunidade escolar em torno das ações dos subprojetos;

732 Educação \& Realidade, Porto Alegre, v. 40, n. 3, p. 725-744, jul./set. 2015. 
6. Desenvolvimento de atividades pedagógicas nas escolas atendidas pelos subprojetos;

7. Produção de material didático-pedagógico e de divulgação;

8. Sistematização e apresentação das experiências construídas em eventos científicos.

\section{O Pibid Diversidade na Escola Municipal da Comunidade Santa Luzia - Contextualização}

Neste item, apresentaremos e discutiremos as ações do Pibid Diversidade desenvolvidas na Escola Municipal da comunidade Santa Luzia, localizada a $30 \mathrm{~km}$ da sede do município de Almenara, MG. Inicialmente, faremos uma breve contextualização do município, da escola e das comunidades do entorno. Os dados aqui apresentados foram levantados pela equipe do subprojeto Pibid Diversidade de Almenara.

Situado no Médio Jequitinhonha, região ao norte do estado de Minas Gerais, o município de Almenara possui 38.775 habitantes, sendo 31.747 habitantes da área urbana e 7.028 da zona rural (IBGE, 2010). De acordo com dados do Atlas de Desenvolvimento Humano no Brasil (Programa das Nações Unidas para o Desenvolvimento, 2013), o Índice de Desenvolvimento Humano (IDH) do município é 0,642, índice considerado baixo em relação à média do estado de Minas Gerais, que é de 0,731 . As principais atividades produtivas são a agropecuária, serviços, comércio e indústria.

Segundo Lopes e Novais (2007), existem no município cerca de 55 comunidades rurais, sendo a maioria dessas formadas por pequenos proprietários e posseiros, que representam $60 \%$ dos proprietários de terra, compondo cerca de $12 \%$ das terras do município. Entre essas comunidades, duas são quilombolas; três são assentamentos, sendo dois financiados pelo programa de crédito fundiário e um formado por decreto de desapropriação; três são acampamentos, sendo um organizado pelo MST (Movimento dos Trabalhadores Rurais Sem Terra) e dois organizados pelo Movimento Sindical de Trabalhadores/as Rurais de Almenara. Nessas comunidades,

[...] existem cerca de 150 famílias e aproximadamente 500 pessoas, sendo que parte delas são pequenos proprietários. Ainda existem empregados em fazendas, principalmente como vaqueiros de médios e grandes proprietários. As famílias basicamente vivem da agricultura familiar, com destaque para a agropecuária: bovino, cultura mista, criação de pequenos animais (galinhas e porcos) e plantação de mandioca, feijão, milho, hortaliças e algumas frutas, como banana, coco, mamão, tangerina e laranja. Alguns prestam serviços aos fazendeiros próximos. Há beneficiários de programas sociais como Bolsa Família e aposentados. Destaca-se a criação de gado, sendo que cerca de $70 \%$ de suas terras estão ocupadas com gado (Lopes, 2013, p. 15). 
Fundada em 1973, por iniciativa de uma moradora da comunidade, Neusa Gondinho Silva, a escola municipal de Santa Luzia atende estudantes do ensino fundamental do $1^{\circ}$ ao $5^{\circ}$ ano e dos anos finais do ensino fundamental do $6^{\circ}$ ao $9^{\circ}$, filhos de agricultores familiares, oriundos das comunidades de Santa Luzia, Umburana, Assentamento Nova Conquista, Barro Branco, Chicote, Boa Vista, Córrego Direito, Morcego e Jenipapo.

Inicialmente, as aulas eram realizadas na casa da sua fundadora. Em 1976, a escola começou a funcionar no prédio atual, construído pela prefeitura municipal em terreno doado por um membro da comunidade, o Sr. Isidoro Alves Meira. Na época, os estudantes que frequentavam as aulas tinham entre 12 e 15 anos de idade.

Em 1994, a escola foi regulamentada pela Portaria CCE n $754 / 94$ para atender estudantes dos anos iniciais do Ensino Fundamental do $1^{\circ}$ ao $5^{\circ}$ ano e, em 2002, regulamentada pela Portaria CEE $n^{\circ} 1628 / 2002$ para atender estudantes dos anos finais do Ensino Fundamental do $6^{\circ}$ ao $9^{\circ}$ ano. Como suporte metodológico, em 2008, a Secretaria de Educação Municipal de Almenara adotou para as escolas do campo o Programa Escola Ativa do MEC $^{1}$ para as classes multisseriadas, ou seja, para os anos iniciais do ensino fundamental $\left(1^{\circ}\right.$ ao $5^{\circ}$ ano). Para os anos finais do ensino fundamental ( $6^{\circ}$ ao $9^{\circ}$ ano), a Secretaria Municipal de Educação lançou o projeto EDICAM - Educação Integral e Integrada no Campo. Iniciado em 2010, o EDICAM tem como objetivo atender às especificidades do campo, partindo da premissa que o campo não é composto por uma realidade única, mas por várias, marcadas por uma diversidade cultural, social, econômica e política. Segundo o projeto pedagógico das escolas do campo de Almenara (Prefeitura Municipal de Almenara, 2010), os princípios pedagógicos do EDICAM contemplam a Pedagogia da Terra ${ }^{2}$, a Pedagogia da Alternância ${ }^{3}$ e a Pedagogia da Autonomia ${ }^{4}$ e têm como base metodológica a interdisciplinaridade, a contextualidade e a formação integral e comunitária.

Em relação aos recursos humanos, a Secretaria de Educação tem um diretor, um supervisor e um inspetor que visitam todas as escolas do campo do município quando solicitados pelos professores que desenvolvem as atividades cotidianas nas escolas.

Na escola onde foi desenvolvido o projeto, no ano de 2012, trabalhavam seis professoras: uma professora graduada em Educação Física; uma graduada em Normal Superior com especialização em Educação do Campo e cursando Matemática; uma cursando História e Geografia; uma graduada em Biologia; uma em Pedagogia com especialização em Educação do Campo; uma graduada em Normal Superior e uma graduada em Normal Superior, cursando Letras/Espanhol com especialização em Educação do Campo. Além das professoras, trabalhavam na escola três serventes responsáveis pela limpeza e alimentação. Durante a semana, as professoras dormiam em um dormitório improvisado na 
escola, uma vez que não havia transporte para elas até a cidade onde residiam, Almenara, localizada a $30 \mathrm{~km}$ de distância da escola.

As docentes eram acompanhadas por professores formadores do município que promoviam reuniões quinzenais para orientação, planejamento e discussão sobre dificuldades encontradas na prática docente. Na escola, eram realizados projetos de intervenção pedagógica nas disciplinas de matemática e português, nos quais os discentes com defasagem na aprendizagem tinham a oportunidade de rever e de fazer a sistematização dos conteúdos já vistos. Esses projetos eram elaborados e coordenados pelas professoras da escola, que contavam com apoio pedagógico dos professores formadores do município.

A gestão dos processos educacionais era centralizada na Secretaria de Municipal de Educação. A elaboração do Projeto Político Pedagógico não contou com a participação das professoras e representantes da comunidade. Ele foi elaborado pela equipe pedagógica das escolas do campo, composta pela diretora das escolas do campo, supervisora, pedagogas e professoras orientadoras de eixos.

Embora a escola atendesse jovens dos assentamentos da região, não contava com a participação efetiva dos movimentos sociais, sindicatos rurais e associações de agricultores, indicando uma baixa articulação com as comunidades locais.

No ano de 2012, a escola tinha em torno de 50 estudantes. Segundo dados obtidos, esses estudantes, com idade variando dos sete aos dezesseis anos, eram filhos de prestadores de serviços aos fazendeiros mais próximos ou de pequenos agricultores familiares que trabalhavam com a bovinocultura, criação de pequenos animais (galinhas e porcos) e plantações de mandioca, feijão, milho, hortaliças e algumas frutas. Suas propriedades estavam localizadas geograficamente em terrenos montanhosos e encostas de vales de difícil acesso, uma vez que, segundo relatos colhidos, os terrenos mais planos e próximos à estrada principal foram ocupados por grandes proprietários de terra que trabalham com a pecuária extensiva.

Como as comunidades de origem dos estudantes estão localizadas nessas regiões de difícil acesso e as estradas vicinais não estão conservadas, a maioria desses estudantes percorria grandes distâncias a pé até chegar à estrada principal e ter acesso ao transporte escolar. Os estudantes da Comunidade Córrego do Chicote, por exemplo, além de andarem longas distâncias, tinham que atravessar o córrego Panela, que transborda na estação das chuvas e impede a passagem.

\section{Estratégias Pedagógicas Desenvolvidas}

As atividades previstas no subprojeto enfocam a metodologia participativa na abordagem de três eixos transversais - trabalho e consumo, saúde e pluralidade cultural - relacionados aos conteúdos pro- 
gramáticos do $6^{\circ}$ ao $9^{\circ}$ ano, em especial àqueles relacionados às áreas de linguagens e códigos (leitura e escrita), ciências e história do ensino fundamental. Em relação aos eixos, há que se considerar que o eixo trabalho e consumo se justifica a partir da identificação da diversidade das relações de trabalhos existentes, suas transformações e permanências no decorrer do tempo histórico e seu vínculo com a realidade local, regional, nacional e mundial. O eixo saúde apresenta-se como uma possibilidade de reconhecimento dos recursos da comunidade voltados para a promoção, proteção e recuperação da saúde nas relações que essa estabelece com meio físico, econômico e sociocultural. E o eixo pluralidade cultural dialoga com os eixos anteriores, reconhecendo a diversidade cultural e linguística como um direito dos povos e dos indivíduos, ao mesmo tempo em que compreende a língua, as linguagens e a memória como construção conjunta, elaborada como tarefa de cada um e de todos, contribuindo para a percepção do campo de possibilidades individuais, coletivas, comunitárias e nacionais.

A escolha desses eixos permite também a sua articulação com o patrimônio cultural imaterial da localidade contemplada no subprojeto. O patrimônio cultural imaterial ou intangível, segundo a concepção da Organização das Nações Unidas para a Educação, a Ciência e a Cultura (Unesco) de 1993, é

\begin{abstract}
[...] o conjunto de manifestações culturais, tradicionais e populares, ou seja, as criações coletivas, emanadas da comunidade, fundadas sobre a tradição. Elas são transmitidas oral e gestualmente, e modificadas através do tempo por um processo de recriação coletiva. Integram esta modalidade de patrimônio as línguas, as tradições orais, os costumes, a música, a dança, os ritos, a medicina tradicional, as artes da mesa e o 'saber fazer' dos artesanatos e das arquiteturas tradicionais (Abreu, 2003, p. 81-82).
\end{abstract}

Para a realização do subprojeto, a escola contou com uma equipe formada por um professor coordenador da UFVJM, uma professora supervisora da escola, que orientou quatro alunos bolsistas de iniciação à docência, regularmente matriculados no curso de Licenciatura Interdisciplinar de Educação do Campo - PROCAMPO/ UFVJM. Além da capacitação docente da professora supervisora e dos estudantes bolsistas; o subprojeto contou com a elaboração de relatórios e diagnósticos institucionais; o mapeamento do patrimônio cultural da região; o desenvolvimento de atividades didático-pedagógicas que articulam os saberes e modos de vida locais; a divulgação de ações e resultados de pesquisa em eventos acadêmico-científicos e a elaboração e publicação de material didático-pedagógico para estudantes e professores de escolas do campo da região.

Com relação à metodologia do trabalho, a equipe do subprojeto encontrava-se mensalmente em Almenara, com a presença do coordenador para planejamento e avaliação das ações realizadas, e semanal- 
mente na escola, com a presença da professora supervisora e estudantes bolsistas. Estes, sob a orientação da professora supervisora, desenvolveram atividades didático-pedagógicas na escola e trabalhos de pesquisas nas comunidades do entorno, com a participação dos estudantes do $6^{\circ}$ ao $9^{\circ}$ ano. Entre os trabalhos de pesquisa realizados, destacamos os seguintes: Levantamento do Patrimônio Material e Imaterial das Comunidades do Entorno da Escola, Novena Literária Vai e Vem na Escola, Sons e Ritmos na Educação do Campo e Resgatando as Cirandas na Educação do Campo.

Por meio da realização desses trabalhos de pesquisa, buscou-se instrumentalizar os professores em formação para o desenvolvimento de práticas pedagógicas articuladas com os saberes locais; capacitá-los na metodologia participativa de investigação científica para a construção e avaliação de instrumentos e de práticas pedagógicas; envolvê-los na discussão de temas curriculares e transversais relacionados aos anos finais do ensino fundamental; proporcionar-lhes experiências metodológicas, tecnológicas e de práticas docentes de caráter inovador e interdisciplinar, visando à superação de problemas identificados no processo de ensino-aprendizagem; desenvolver reflexão crítica entre os estudantes da comunidade escolar sobre os temas pesquisados e valorizar a vida no campo, os saberes locais e a diversidade cultural das comunidades do entorno. Os resultados dos trabalhos de pesquisa foram publicados no Almanaque Saberes do Campo (Marques; Ferraz; Carvalho, 2013), que foi distribuído para a comunidade escolar e outras escolas do campo do município no encerramento do subprojeto.

Entre as ações realizadas em 2012, destacamos a Sessão de Cinema, as Oficinas Memórias e a Feira Cultural, que contaram com a intensa participação da comunidade escolar, de familiares e membros das comunidades do entorno.

Na Sessão de Cinema, foi exibido o filme Vida de Menina, de Helena Solberg (2003), contando o dia a dia de uma adolescente que habitava na cidade de Diamantina, em Minas Gerais, entre 1893 e 1895, e que escrevia um diário. Essa atividade tinha como objetivo incentivar a prática da leitura e pesquisa entre os estudantes, além de motivá-los a fazer seus próprios relatos. Estes resultaram na construção do caderno da realidade ${ }^{5}$, instrumento pedagógico amplamente utilizado nas Escolas da Família Agrícola (EFAs). Esse gênero textual, chamado pelos estudantes da escola de Caderno do Pibid, foi trabalhado em sala de aula com a orientação da professora supervisora e dos estudantes bolsistas e, em casa, com a contribuição de familiares e membros das comunidades. Nos cadernos, além dos resultados de pesquisas realizadas nas comunidades, há relatos dos estudantes sobre família, estudo, trabalho, o papel da escola em suas vidas, suas experiências do dia a dia, a história dos lugares onde vivem, suas dificuldades e suas perspectivas de vida. Para a escrita do caderno da realidade, adotou-se a abordagem da escrita processual, envolvendo planejamento, escrita, revisão e edição, o que 
gerou um impacto positivo na leitura e produção de textos e estimulou entre os estudantes a reflexão crítica sobre os temas tratados. A nosso ver, a elaboração dos cadernos foi uma experiência de aprendizagem enriquecedora tanto para os estudantes da escola quanto para os licenciandos, uma vez que favoreceu o protagonismo desses no processo de construção de conhecimento. Este fato pode ser observado no seguinte relato:

O que eu achei muito importante no Pibid foram as descobertas sobre a minha comunidade, porque meus pais moram na comunidade Umburana desde quando nasceram e não sabíamos nada sobre ela. E agora, com as pesquisas Pibid, já troco informações com os meus colegas (Relato de aluna do $7^{\circ}$ ano, de 12 anos, da comunidade Umburana).

Nas Oficinas Memórias, foram desenvolvidas, por meio de grupos de trabalho, pesquisas para o levantamento do patrimônio material e imaterial das comunidades do entorno. Foram levantados costumes, remédios caseiros, receitas da culinária regional, causos, relatos de vida e reflexões sobre a escola do e no campo. As pesquisas de campo envolveram os familiares dos estudantes e as pessoas da comunidade que contribuíram de modo expressivo com ideias e informações. O resultado desse trabalho foi sistematizado e apresentado por meio de cartazes que foram expostos na escola e da publicação do Almanaque Saberes do Campo (Marques; Ferraz; Carvalho, 2013).

Ressaltamos que as Oficinas Memórias permitiram aos estudantes uma oportunidade para trabalhar no currículo escolar, geralmente importado da escola urbana, os costumes locais, as suas crenças, tradições orais e expressões artísticas em geral, como a música, a dança e o artesanato da região. Segundo Arroyo (1999),

A cultura hegemônica trata os valores, as crenças, os saberes do campo de maneira romântica ou de maneira depreciativa, como valores ultrapassados, como saberes tradicionais, pré-científicos, pré-modernos. Daí que o modelo de educação básica queira impor para o campo currículos da escola urbana. A cultura hegemônica trata os valores, as crenças, os saberes do campo de saberes e valores urbanos, como se o campo e sua cultura pertencessem a um passado a ser esquecido e superado (Arroyo, 1999, p. 23).

Na Feira Cultural realizada como atividade de encerramento do $1^{\circ}$ ano de projeto, foi evidenciado o papel da escola do campo enquanto espaço aglutinador da comunidade. Pais de alunos e pessoas da comunidade contribuíram na organização do evento, emprestando artefatos para a exposição, fazendo biscoitos e doces caseiros, trazendo relatos de vida, contando causos etc. Os estudantes, por sua vez, apresentaram uma peça de teatro, danças regionais, canções cantadas em coro, repentes, poesias, entre outros.

738 Educação \& Realidade, Porto Alegre, v. 40, n. 3, p. 725-744, jul./set. 2015. 
Hoje eu amei o meu dia na escola. Dia de Pibid. Dancei a música da mulher rendeira. Tudo tem sido tão divertido. Eu sinto que esse projeto Pibid está unindo a minha escola e nós, alunos e professores, sentimos mais vontade de estudar. Estou amando tudo (Relato de aluna do $6^{\circ}$ ano, de 12 anos, da Comunidade Boa Vista).

\section{Considerações Finais}

Destacamos neste artigo o grande desafio que o Brasil tem para formar docentes, de modo a atender às múltiplas demandas da educação brasileira e superar o descaso histórico das políticas públicas em relação às camadas da população que permaneceram à margem dos projetos de desenvolvimento do país. Nesse contexto, é dever da sociedade como um todo encontrar alternativas que revertam o quadro deplorável da educação básica no Brasil, para o qual não há soluções hegemônicas que possam ser aplicadas de forma indiscriminada e descontextualizada. Ao contrário, numa sociedade plural, as soluções devem advir da diversidade, do diálogo construtivo e participativo de todos os sujeitos sociais. Um projeto de educação transformador e inclusivo só é possível com o engajamento de todos os atores envolvidos nesse processo. Portanto, a formação de professores deve superar o isolamento acadêmico, teórico e ideológico e se expandir para além da universidade.

Com essa perspectiva, entendemos que os projetos de formação de professores para o ensino básico devem ocorrer de forma articulada com a escola pública, o que de certa forma tem sido favorecido pelo Pibid. No âmbito da educação do campo, essa articulação tem especificidades que devem ser consideradas. O potencial que as escolas do campo têm de agregar a comunidade ampliam o seu papel político e comunitário. A escola do campo não é somente um espaço institucional de ensino, ela é, sobretudo, um espaço de convergência da comunidade campesina, um lugar de encontro e de trocas, um lugar que permite o trabalhador rural criar seus filhos perto de sua moradia, do seu trabalho e do seu contexto de vida. Ao trabalharmos com a escola do campo, trabalhamos também com a sua comunidade e os sujeitos sociais que a compõem. Portanto, se faz necessário que a formação do professor possibilite o desenvolvimento de habilidades para realizar articulações que fortaleçam a organicidade dessas comunidades.

Na experiência desenvolvida com o Pibid Diversidade na comunidade Santa Luzia, foi possível verificar a importância que a escola do campo tem na manutenção das comunidades rurais, o seu papel mobilizador e catalisador de processos de construção identitária. Com o trabalho realizado nesse subprojeto, foi possível resgatar, em conjunto com a comunidade, elementos do seu patrimônio material e imaterial que, ao serem compilados, discutidos e reapresentados à comunidade, desencadearam um processo de reapropriação de elementos da identidade local. A escola torna-se palco para o processo de ressignificação 
da comunidade e nesse processo também se ressignifica. $\mathrm{O}$ olhar da comunidade para a escola muda ao ver-se reconhecida, valorizada e integrada ao processo de ensino e construção de conhecimento. Muda também o olhar do estudante para a sua comunidade, que passa a ser respeitada, ouvida e valorizada, tornando-se uma referência para o seu processo de formação.

Do ponto de vista da formação inicial do educador do campo, a experiência construída com o projeto Pibid Diversidade possibilitou uma mudança expressiva na atitude dos licenciandos em relação à sua trajetória formativa. Dois aspectos desse processo merecem destaque. A dificuldade inicial de sair de um modelo de formação no qual predomina a reflexão teórica para uma situação de aprendizado que se dá no fazer, aprender fazendo. $\mathrm{O}$ confronto com a realidade da escola do campo e sua comunidade apresentou desafios que levaram os discentes a construir alternativas e a pensar sobre elas. O processo de ação-reflexão-ação criou condições para que os discentes assumissem um papel de protagonismo no seu processo de formação.

O segundo aspecto a ser destacado é a mudança de percepção em relação à escola e à perspectiva de atuação profissional no magistério. No grupo de licenciandos que participaram desse subprojeto, foi possível verificar uma maior vinculação com a escola do campo e um maior comprometimento com a carreira docente.

Em relação aos docentes da escola, é importante sinalizar o papel do professor supervisor. Na nossa avaliação, esse é um dos aspectos fundamentais do Pibid. Primeiro porque engaja o professor da escola pública no processo de formação de novos professores, e ao fazê-lo, valoriza a experiência e os saberes construídos em sala de aula. Segundo, ao oferecer auxílio financeiro por meio de bolsas, abre a possibilidade para esse professor se dedicar mais à escola e, em alguns casos, permite que ele deixe de cumprir jornada dupla para garantir o seu sustento. Observamos, não somente no subprojeto da comunidade Santa Luzia como nos outros subprojetos, um grande comprometimento dos professores supervisores, tanto com as atividades desenvolvidas como também com a escola e sua comunidade. Terceiro, o contato constante do supervisor com o coordenador de área e a participação nos eventos do Pibid promovidos pela universidade tornou-se uma ponte para a formação continuada. Percebemos que a distância da universidade foi diminuindo ao longo do projeto. Inicialmente, os supervisores se colocavam timidamente, como se o espaço universitário não lhes coubessem. À medida que foram estimulados a relatar e a sistematizar as suas experiências, a participar de eventos científicos, a construir materiais didáticos e foram observando os resultados das atividades realizadas nas escolas, ganharam confiança e assumiram uma atitude de maior protagonismo. Um indicador importante desse processo é que dos oito supervisores envolvidos nos subprojetos, três se preparam para dar continuidade à sua formação, estimulados pela experiência com o Pi- 
bid. Por último, é preciso destacar o fator de contágio que o supervisor desencadeia na comunidade escolar. Observamos que a sua experiência com o Pibid despertou o interesse dos colegas e dos gestores da escola e do município. Nas atividades desenvolvidas, verificamos a participação ativa do corpo docente, da direção, do grupo de funcionários e dos gestores municipais. Nesse sentido, entendemos que a abrangência do Pibid Diversidade não se restringiu a um professor e suas turmas, alcançando também, uma dimensão institucional e comunitária, o que pode ampliar a possibilidade da continuidade das ações construídas.

Embora os resultados apresentados sejam promissores, entendemos que o Pibid Diversidade, enquanto programa de iniciação à docência voltado para as escolas do campo e indígenas, deve avançar em relação a alguns aspectos fundamentais para esses projetos de educação. A articulação da escola com os atores sociais, movimentos, associações, sindicatos entre outros, é fundamental para o estabelecimento de uma educação participativa de caráter identitário. Como fortalecer esse diálogo? Como inserir esses atores de forma sistemática nas ações desenvolvidas pelos projetos Pibid? Como estabelecer nas escolas um diálogo permanente com a comunidade?

Embora em um primeiro momento o fortalecimento do vínculo da universidade com as escolas do campo tenha sido um passo importante, ainda temos o desafio em relação criação de espaços educacionais participativos. Nessa direção, encontram-se inúmeros obstáculos, a começar pela gestão centralizada das escolas brasileiras e seus processos autoritários e excludentes, assim como as limitações impostas nos editais Pibid Diversidade que, em certos aspectos, revelam pouca sensibilidade para a complexidade das escolas localizadas em áreas rurais.

Recebido em 20 de março de 2014 Aprovado em 02 de maio de 2015

\section{Notas}

1 O Programa Escola Ativa teve início em 1997, com objetivo de diminuir a evasão e a retenção nas escolas rurais por meio da capacitação dos docentes para atuarem nas escolas multisseriadas do norte e nordeste do Brasil. Inicialmente, esteve vinculado ao FNDE/MEC com recursos do Banco Mundial. Em 2007, o programa passa a ser gerenciado pela SECAD com recursos do próprio MEC. Em 2008, o programa sofre expansão com a adesão de 3.106 municípios, vindo a atingir, em 2010, a 10.000 escolas em todo o Brasil. De inspiração escolanovista, o programa entra em conflito com os princípios básicos da educação do campo, o que resulta na Nota Técnica emitida pelo FONEC, em 2011, sugerindo profundas reformulações e o redirecionamento do mesmo.

2 A Pedagogia da Terra, ou Ecopedagogia, é um conceito ainda em construção e parte da noção de sustentabilidade ou de desenvolvimento sustentável para configurar um movimento pedagógico que vai desde a abordagem curricular até a organização social e política. De inspiração freiriana, tem por objetivo 
promover a aprendizagem do sentido das coisas nos contextos da vida quotidiana. Tem como perspectiva o desenvolvimento de um novo modelo de civilização sustentável (Gadotti, 2005).

3 A Pedagogia da Alternância consiste na organização do ensino escolar em diferentes tempos e espaços, contemplando diversas experiências formativas. Esse método começou a ser formulado na França, em 1935, em decorrência das insatisfações de um pequeno grupo de agricultores com o sistema educacional de seu país. No Brasil, a Pedagogia da Alternância começou a ser empregada em 1969 no estado do Espírito Santo, onde foram construídas as três primeiras Escolas Famílias Agrícolas. A ideia central é conciliar os estudos com as atividades no meio socioprofissional. Na escola, focaliza-se o conhecimento acumulado, e no trabalho familiar as experiências concretas dos educandos no seu contexto de vida. Além das disciplinas escolares básicas, são trabalhadas as temáticas relativas à vida associativa e comunitária, ao meio ambiente e à formação integral nos meios profissional, social, político e econômico (Teixeira; Bernartt; Trindade, 2008).

4 A Pedagogia da Autonomia, proposta por Paulo Freire, em 1996, trata da prática pedagógica do professor em relação à autonomia de ser e de saber do educando. O processo educativo deve reconhecer e respeitar o conhecimento prévio do aluno, os seus saberes e práticas socialmente construídas. Nessa perspectiva, educar vai além da mera transmissão de conhecimentos, educar é criar oportunidades para a construção de saberes, de modo que o aprendiz se torne sujeito do seu conhecimento. A relação professor aluno é marcada pela mutualidade no aprendizado.

50 caderno da realidade é um instrumento utilizado na Pedagogia da Alternância, em que o aluno registra suas reflexões acerca da sua realidade, visando à sistematização das principais questões discutidas no Plano de Estudo. Em geral, é composto dos seguintes registros: síntese individual, síntese geral, uma discussão sobre o Plano de Estudo e a Folha de Observação. É realizado ao longo da vida escolar, possibilitando ao educando sistematizar sua história de vida, retomar questões discutidas em momentos anteriores e, por meio do exercício da pesquisa, da reflexão e do registro, amadurecer intelectualmente.

\section{Referências}

ABREU, Regina. "Tesouros Humanos Vivos" ou quando as Pessoas Transformam-se em Patrimônio Cultural: notas sobre a experiência francesa de distinção dos "Mestres da Arte". In: ABREU, Regina; CHAGAS, Mário (Org.). Memória e Patrimônio: ensaios contemporâneos. Rio de Janeiro: DP\&A, 2003. P. 81-94.

ARROYO, Miguel Gonzalez; FERNANDES, Bernardo Mançano. A Educação Básica e o Movimento Social do Campo. Brasília: Articulação Nacional Por Uma Educação Básica do Campo, 1999.

BATISTA, Aline Cleide; SILVA JUNIOR, Paulo Melgaço da; CANEN, Ana. Em Busca de um Diálogo entre Plano Nacional de Educação (PNE), Formação de Professores e Multi/Interculturalismo. Ensaio: avaliação e políticas públicas em educação, Rio de Janeiro, v. 21, n. 79, p. 253-267, abr./jun. 2013.

BRASIL. Coordenação de Aperfeiçoamento de Pessoal de Nível Superior (CAPES). Pibid Diversidade. Brasília, set. 2013. Disponível em: <http://www.capes. gov.br/educacao-basica/capespibid/pibid-diversidade>. Acesso em: 04 out. 2013. 
BRASIL. Instituto Nacional de Estudos e Pesquisas Educacionais Anísio Teixeira (INEP). Censo da Educação Básica 2012 - resumo técnico. Brasília: Instituto Nacional de Estudos e Pesquisas Educacionais Anísio Teixeira, 2013. Disponível em: <http://download.inep.gov.br/educacao_basica/censo_escolar/resumos_ tecnicos/resumo_tecnico_censo_educacao_basica_2012.pdf $>$. Acesso em: 15 set. 2013.

BRASIL. Instituto Nacional de Estudos e Pesquisas Educacionais Anísio Teixeira (INEP). Sinopse Estatística da Educação Básica de 2014. Planilhas 2.6-2.7. Brasília, 2014. Disponível em: <http://portal.inep.gov.br/basica-censo-escolar-sinopse-sinopse>. Acesso em: 20 abr. 2015.

BRASIL. Conselho Nacional de Educação/Câmara de Educação Básica. Diretrizes Operacionais para a Educação Básica nas Escolas do Campo. Resolução n. 1 de 03 de abril de 2002. P. 8.

BRASIL. Lei no 9.394, de 20 de dezembro de 1996. Estabelece as Diretrizes e Bases da Educação Nacional. Diário Oficial [da República Federativa do Brasil], Brasília, DF, v. 134, n. 248, 23 dez. 1996. Seção 1. P. 27834-27841.

FUNDAÇÃO CARLOS CHAGAS. Um Estudo Avaliativo do Programa Institucional de Iniciação à Docência (Pibid). São Paulo: Fundação Carlo Chagas, 2014. Disponível em: <http://www.capes.gov.br/images/stories/download/ bolsas/24112014-pibid-arquivoAnexado.pdf>. Acesso em: 20 abr. 2015.

GADOTTI, Moacir. Pedagogia da Terra e Cultura de Sustentabilidade. Revista Lusófona de Educação, Lisboa, v. 6, n. 6, p. 15-19, 2005.

IBGE (Instituto Brasileiro de Geografia e Estatística). Censo Demográfico 2010: Características da População e dos Domicílios. Disponível em: <http://www. ibge.gov.br/cidadesat>. Acesso em: 15 abr. 2012.

LOPES, Edivaldo Ferreira. Fatos Históricos e Caracterização das Comunidades do Entorno da Escola Boa Sorte 1. In: MARQUES, Luiz Otávio Costa; FERRAZ, Fabiane Rodrigues; CARVALHO, Vanúbia Monteiro (Org.). Almanaque Saberes do Campo. 2013. P. 13-15. Disponível em: <http://Pibidufvjm.webnode.com> Acesso em: 02 out. 2013.

LOPES, Edivaldo Ferreira; NOVAIS, Luziete Rodrigues. Tudo pelo Boi: a pecuária e suas consequências. 2007. 67 f. Trabalho de Conclusão de Curso (Extensão Rural) - PUC Minas, Belo Horizonte, 2007.

MARQUES, Luiz Otávio Costa; FERRAZ, Fabiane Rodrigues; CARVALHO, Vanúbia Monteiro (Org.). Almanaque Saberes do Campo. 2013. Disponível em: $<$ http://Pibidufvjm.webnode.com>. Acesso em: 02 out. 2013.

NASCIMENTO, Claudemiro Godoy. Educação do Campo e a Teoria Crítica em Gramsci. Cadernos de Pesquisa Pensamento Educacional, Curitiba, v. 4, p. 97116, 2009.

PENIN, Sônia Teresinha de Souza. A Formação de Professores e a Responsabilidade das Universidades. Estudos Avançados, São Paulo, v. 15, n. 42, p. 317-332, 2001.

PREFEITURA MUNICIPAL DE ALMENARA. Secretaria Municipal de Educação. Projeto Político Pedagógico das Escolas do Campo. Almenara: Secretaria Municipal de Educação, 2010.

PROGRAMA DAS NAÇÕES UNIDAS PARA O DESENVOLVIMENTO. Atlas do Desenvolvimento Humano no Brasil. 2013. Disponível em: <http://www.atlasbrasil.org.br/2013/pt/o_atlas/o_atlas_/>. Acesso em: 05 out. 2013. 
ROCHA, Eliene Novaes Rocha; PASSOS, Joana Célia dos; CARVALHO, Raquel Alves. Educação do Campo: um olhar panorâmico. s/d. Disponível em: <http:// www.gepec.ufscar.br/textos-1/textos-educacao-do-campo/educacao-do-campo-um-olhar-panoramico/view>. Acesso em: 29 set. 2013.

SANTOS, Milton. Da Totalidade ao Lugar. São Paulo: EDUSP, 2001.

SILVA, Irizelda Martins de Souza. Formação de Professores no e do Campo e a UNESCO: uma nova estratégia? Cadernos de Pesquisa Pensamento Educacional, Curitiba, v. 5, p. 88-106, 2010.

TEIXEIRA, Edival Sebastião; BERNARTT, Maria de Lourdes; TRINDADE, Glademir Alves. Estudos sobre Pedagogia da Alternância no Brasil: revisão de literatura e perspectivas para a pesquisa. Educação e Pesquisa, São Paulo, v. 34, p. 227-242, maio/ago. 2008.

VIDA de Menina. Direção: Helena Solberg. Raccord Produções/Radiante Filmes. Brasil, 2003. 1 DVD (101 min), color.

Paulo Afranio Sant'Anna é professor adjunto da Licenciatura em Educação do Campo da UFVJM. Mestre e doutor em Psicologia pela Universidade de São Paulo. Faz parte do corpo permanente do Mestrado Profissional Educação e Saúde da UFVJM e é professor colaborador do Mestrado Profissional PROMESTRE da UFMG. É coordenador institucional do Pibid Diversidade da UFVJM.

E-mail:pa.annal@gmail.com

Luiz Otávio Costa Marques é professor de língua inglesa da Licenciatura em Educação do Campo da Universidade Federal dos Vales de Jequitinhonha e Mucuri, Minas Gerais. Graduado e mestre em Estudos Linguísticos e Literários em Inglês pela Universidade de São Paulo. Desenvolveu programas de formação de professores de língua inglesa sob a ótica das teorias dos Novos Letramentos e Multiletramentos. Participou dos grupos de pesquisa Ensinar no Vale e Novos Letramentos em Língua Inglesa, cadastrados no CNPq. É coordenador de área do subprojeto Pibid Diversidade da UFVJM. E-mail: luizocmarques@gmail.com 